\title{
Prognostic Usefulness Of Advanced Lung Cancer Inflammation Index In Locally-Advanced Pancreatic Carcinoma Patients Treated With Radical Chemoradiotherapy
}

This article was published in the following Dove Press journal:

Cancer Management and Research

\author{
Erkan Topkan (iD) \\ Huseyin Mertsoylu ${ }^{2}$ \\ Yurday Ozdemir ${ }^{1}$ \\ Ahmet Sezer $\mathbb{D}^{2}$ \\ Ahmet Kucuk $^{3}$ \\ Ali Ayberk Besen ${ }^{2}$ \\ Ozgur Ozyilkan ${ }^{2}$ \\ Ugur Selek (iD ${ }^{4,5}$
}

'Department of Radiation Oncology, Baskent University Medical Faculty,

Adana, Turkey; ${ }^{2}$ Department of Medical

Oncology, Baskent University Medical

Faculty, Adana, Turkey; ${ }^{3}$ Department of Radiation Oncology, Mersin City

Hospital, Mersin, Turkey; ${ }^{4}$ Department of Radiation Oncology, Koc University

School of Medicine, Istanbul, Turkey;

${ }^{5}$ Department of Radiation Oncology, The

University of Texas, MD Anderson

Cancer Center, Houston, TX, USA
Correspondence: Erkan Topkan

Department of Radiation Oncology,

Baskent University Medical Faculty, Adana

0II20, Turkey

Tel +90-533-7381069

$\mathrm{Fax}+90-322-3444452$

Email docdretopkan@gmail.com
Background/Aims: Previously advanced lung cancer inflammation index (ALI) has been demonstrated to have prognostic utility in the stratification of patients into distinctive survival groups, but the prognostic value of ALI has never been explored in the setting of locally advanced pancreatic carcinomas (LAPC) treated with concurrent chemoradiotherapy (CCRT). Hence, we aimed to investigate the prognostic value of pre-treatment ALI in LAPC patients who underwent radical CCRT.

Methods: Present retrospective cohort analysis incorporated 141 LAPC patients who received radical CCRT. Accessibility of baseline ALI cutoff(s) impacting survival outcomes was sought by receiver operating characteristic (ROC) curve analysis. Interaction between the ALI and overall- (OS) and progression-free survival (PFS) comprised our primary and secondary endpoints, respectively.

Results: At a median follow-up of 14.4 months (range: 3.2-74.2), the median PFS and OS were 7.5 (\%95 CI: 5.9-9.1) and 14.6 months (\%95 CI: 11.6-17.6), respectively. ROC curve analyses set the ideal ALI cutoff value at 25.3 (AUC: $75.6 \%$; sensitivity: $72.7 \%$; specificity: $70.3 \%$ ) that exhibited significant associations with both the OS and PFS results. Patient stratification into two groups per ALI $[\leq 25.3(\mathrm{~N}=75)$ versus $>25.3(\mathrm{~N}=66)]$ showed that the ALI $>25.3$ group had significantly superior median OS (25.8 versus 11.4 months; $\mathrm{P}<0.001$ ) and PFS (15.9 versus 6.0 months; $\mathrm{P}<0.001)$ durations than its $\mathrm{ALI} \leq 25.3$ counterpart. Other factors exhibiting significantly better OS and PFS rates were $\mathrm{N}_{0}$ stage (versus $\mathrm{N} 1 ; \mathrm{P}<0.05$ for each endpoint) and CA $19-9 \leq 90 \mathrm{U} / \mathrm{mL}$ (versus $>90 \mathrm{U} / \mathrm{mL} ; \mathrm{P}<0.05$ for each endpoint), respectively. These three factors were additionally asserted to be independent indicators of longer OS ( $\mathrm{P}<0.05$ for each) and PFS ( $\mathrm{P}<0.05$ for each) in multivariate analyses.

Conclusion: Results of this hypothesis-generating research proposed the pre-CCRT ALI as a novel robust associate of OS and PFS outcomes for LAPC patients undergoing CCRT.

Keywords: locally-advanced pancreas cancer, advanced lung cancer inflammation index, concurrent chemoradiotherapy, prognosis, survival outcomes

\section{Introduction}

Pancreatic carcinoma (PC) is one of the leading sources of cancer-related mortality in Europe and the United States, with overall annual incidence and mortality rates being practically equivalent. ${ }^{1,2}$ Although the radical surgery offers the best cure chance, only $20 \%$ of all PCs present with resectable disease, while remaining $30 \%$ 
and $50 \%$ are diagnosed with an unresectable locally advanced- (LAPC) or metastatic PCs, respectively. ${ }^{3}$ Sequential chemoradiotherapy and definitive concurrent chemoradiotherapy (CCRT) are the two current treatment choices for medically fit LAPC patients, ${ }^{4,5}$ but sadly, the prognosis of such patients remains still grim with an expected median survival of only around 1 year or indeed less even with such aggressive treatments. ${ }^{2,6}$

Pointing out its critical roles in initiation, progression and dissemination steps of carcinogenesis; inflammation has been appreciated as the seventh hallmark of cancer as it can facilitate the acquisition of other hallmarks. ${ }^{7}$ Therefore, inflammation is relevant both as a risk factor for cancer development and as a reactionary process of cancer: patients with chronic pancreatitis carry a 13-fold higher risk of PC development. ${ }^{8}$ Furthermore, considerable amounts of evidence proposed the systemic inflammation as a basic factor underlying the distinctive patient prognoses following indistinguishable treatment schemes. ${ }^{9-14}$ Hence, the prognostic worth of various systemic inflammation markers has been explored in PC patients; including the neutrophil-lymphocyte ratio (NLR), platelet-lymphocyte ratio (PLR), lymphocyte-monocyte ratio (LMR), Glasgow prognostic score (GPS), prognostic nutritional index (PNI), and systemic inflammation response index (SIRI). ${ }^{15-23}$

Recently, Jafri et al reported the advanced lung cancer inflammation index (ALI) as another useful prognosticator in metastatic non-small-cell lung cancer patients, ${ }^{24}$ which has been subsequently shown to exert comparable prognostic incentive in esophageal-, small-cell lung-, head and neck squamous cell-, metastatic colorectal cancers, and diffuse large B-cell lymphomas. ${ }^{25-29}$ However, to our best knowledge, the prognostic value of ALI has never been addressed in unresectable LAPCs treated with definitive C-CRT. Thus, present retrospective analysis aimed to investigate the prognostic value of baseline ALI values in LAPC patients who received definitive C-CRT.

\section{Patients And Methods}

\section{Patient Population}

We retrospectively reviewed our institutional database maintained and updated by Baskent University Medical Faculty Department of Radiation Oncology to identify unresectable LAPCs treated with radical CCRT between January 2007 and December 2017. Referencing the AJCC staging system (7th ed.), we defined an unresectable LAPC as a primary tumor involving the celiac axis and/or superior mesenteric artery, in particular, the stage III $\left(\mathrm{T}_{4} \mathrm{~N}_{0-1} \mathrm{M}_{0}\right)$ disease. The standard diagnostic and staging workup was as previously reported elsewhere. ${ }^{30,31}$ For each patient, the gross tumor volume included the primary tumor and involved lymph nodes apparent on contrastenhanced CT (short axis $\geq 1.0 \mathrm{~cm}$ ) and/or PET images, while nodes $<1.0 \mathrm{~cm}$ were only included if they were judged to be metabolically active (maximum standard uptake value $>2.5$ ) on PET scan. For eligibility, patients had to meet the following requirements as well: age 18 to 80 years, Eastern Cooperative Oncology Group (ECOG) performance status $0-1$, histological adenocarcinoma proof, no previous chemotherapy/RT history, adequate bone marrow and hepatic and renal functions, and body mass index $(\mathrm{BMI})>20 \mathrm{~kg} / \mathrm{m}^{2}$.

\section{Ethics, Consent And Permissions}

The study was conducted by following the Helsinki Declaration and Rules of Good Clinical Practice, and the study design was approved by the Institutional Ethical Committee review board of Baskent University Medical Faculty before any data collection. According to our institutional standards, all patients provided written informed consent before the initiation of treatment either themselves or legally authorized representatives for collection and analysis of blood samples, pathologic specimens, and publication of their outcomes.

\section{Concurrent Chemoradiotherapy}

All patients underwent definitive CCRT as reported previously. ${ }^{30,31}$ In brief, a dose of $45 \mathrm{~Gy}(1.8 \mathrm{~Gy} /$ fraction, 5 days/week, for 5 weeks) enclosed the defined planning target volume. Patients treated with elective nodal irradiation were excluded from the analysis. Concurrent with the radiotherapy, all patients received 1-2 courses of cisplatin $(\mathrm{N}=37)$, oral capecitabine $(\mathrm{N}=35)$, continuously infused 5 -fluorouracil $(\mathrm{N}=29)$, gemcitabine $(\mathrm{N}=21)$, or cisplatinbased doublet chemotherapy $(\mathrm{N}=19)$. Of those patients, 76 of them received additional 4-6 courses of maintenance gemcitabine $(\mathrm{N}=34)$ or $2-4$ courses of cisplatin-based doublet $(\mathrm{N}=42)$ chemotherapy following C-CRT.

\section{Advanced Lung Cancer Inflammation Index Measures}

We calculated the ALI by utilizing the total blood count and biochemistry tests obtained on the first day of C-CRT as per 
the Jafri's original definition: ALI $=\mathrm{BMI}(\mathrm{kg} / \mathrm{m} 2) \times$ Albumin (g/dL)/NLR. ${ }^{24}$

\section{Treatment Response Evaluation}

Patients were examined every 3 months for the first 2 years and at 6-month interims, or more frequently, from thereon. Treatment response was first evaluated at 3 months of CCRT by using restaging PET/CT and abdominal MRI/CT scans and the criteria defined by the EORTC 1999 guidelines. Then, each patient was monitored every 3 months for the first 2 years and every 6 months thereafter by total blood count and biochemistry tests, serum CA 199 concentrations, and PET/CT until the confirmation of complete metabolic response and abdominal MRI/CT scans in cases with a confirmed complete metabolic response. Patients underwent abdominal ultrasonography, chest CT, cranial MRI, bone scintigraphy examinations, only if indicated.

\section{Statistical Analysis}

The primary endpoint of the present analysis was to assess the overall survival (OS: the interval between the first day of CCRT and the dates of death/last follow-up) difference between the patients with high versus low pre-CCRT ALI values. The progression-free survival (PFS: the interval between the first day of CCRT and the dates of any type of disease progression/death/last follow-up) constituted the secondary endpoint. Continuous variables were described with medians and ranges, while frequency distributions were used for categorical variables. Correlations between different groups were compared by Chi-square tests, Student's t-tests, or Spearman correlations, as appropriate. Receiver operating characteristic (ROC) curve analysis was used to determine the accessibility of pre-CCRT ALI cutoff that may stratify the study population into two ALI groups with significantly different OS and PFS results. The potential influence of different risk factors and OS and PFS were analyzed with Kaplan-Meier estimates and log rank tests. Only the factors exhibiting significance on univariate comparisons were included in the multivariate Cox proportional hazard model for assessing the potential interactions between these variables and survival results. For intergroup comparisons, two-sided P-values <0.05 were considered significant.

\section{Results}

A total of 141 patients were included in this retrospective cohort analysis (Table 1). The median age was 56 years (range; 32-79 years) for the whole study population with 26 (18.4) of them being $>70$ years of age. The tumor was mostly confined to the pancreatic head $(\mathrm{N}=115 ; 81.6 \%)$, while lymph node status was N1 in 65 (46.1\%) cases. The CA 19-9 level was higher than $>90 \mathrm{U} / \mathrm{mL}$ in $99(70.2 \%)$ patients, which was defined as the critical cutoff in the benchmark The Charité Onkologie 001 (CONKO-001) randomized trial. ${ }^{32}$

Median follow-up time was 14.4 months (range: 3.2-74.2) for all patients, and $43(30.5 \%)$ of them were still alive during this final analysis. Locoregional disease control was achieved in $43(30.5 \%)$ patients and $22(15.6 \%)$ patients were free of any disease progression. The median, 2- and 4-year survival rates were 7.5 months, $19.3 \%$, and $10.9 \%$ for PFS, and 14.6 months, $31.5 \%$, and $21.1 \%$ for OS, respectively (Figure 1).

Using ROC curve analysis, we sought for the presence of separate relevant cutoff(s) for baseline ALI measures which may interact with OS and PFS outcomes in significant manners. Our search revealed ideal cutoffs at 25.3 [Area under the curve (AUC): 75.6\%; Sensitivity: 72.7\%; Specificity: 70.3\%] and 25.5 (AUC: 76.1\%; Sensitivity: 74.4\%; Specificity: 71.4\%) points for PFS and OS, respectively (Figure 2A and B). Because the two values are very similar, we chose the 25.3 as the single common cutoff and grouped the patients into 2 ALI gatherings for further comparative analysis: $\mathrm{ALI} \leq 25.3(\mathrm{~N}=75)$ and $\mathrm{ALI}>25.3$ $(\mathrm{N}=66)$. Comparative survival analyses per ALI groups exhibited significantly superior median PFS (15.9 versus 6.0 months; $\mathrm{P}<0.001)$ and $\mathrm{OS}(25.8$ versus 11.4 months; $\mathrm{P}<0.001$ ) times favoring the ALI $>25.3$ group (Figure $2 \mathrm{C}$ and D). We additionally examined the accessibility of a potential link between the ALI grouping and the locoregional response rates after CCRT. However, despite the actuarial 1-year locoregional progression-free rates numerically favored the ALI $>25.3$ group over its $\mathrm{ALI} \leq 25.3$ counterpart $(37.3 \%$ versus $28.8 \%$; $\mathrm{P}=0.16)$, yet this difference could not reach statistical significance which might be associated with our limited population size rather than proposing no relationship between these two parameters.

Univariate analysis comprising the factors in Table 1, revealed the N0 stage (versus N1), CA 19-9 $\leq 90 \mathrm{U} / \mathrm{mL}$ (versus $>90 \mathrm{U} / \mathrm{mL}$ ), and ALI $>25.3$ (versus $\leq 25.3$ ) as the factors exhibiting significant association with longer median OS and PFS durations and numerically superior 2- and 4-year OS and PFS rates (Tables 2 and 3). In a multivariate analysis restricted to these 3 factors, all factors retained their independent prognostic significance on both of the 
Table I Baseline Demographics Of I4I Patients With Locally-Advanced Pancreas Cancer

\begin{tabular}{|c|c|c|c|c|}
\hline Characteristics & All Patients $(N=|4|)$ & $A L I \leq 25.3(N=75)$ & ALI >25.3 $(\mathrm{N}=66)$ & P-Value \\
\hline Median age, years (range) & $56(32-79)$ & 55 (32-79) & $57(33-78)$ & 0.71 \\
\hline \multicolumn{5}{|l|}{ Age group (N; \%) } \\
\hline$<70$ years & $115(81.6)$ & $60(80.0)$ & $55(83.3)$ & 0.32 \\
\hline$\geq 70$ years & $26(18.4)$ & I5 (20.0) & II (I6.7) & \\
\hline \multicolumn{5}{|l|}{ Gender (N; \%) } \\
\hline Female & $30(21.3)$ & $16(21.4)$ & $14(2 \mid .2)$ & 0.93 \\
\hline Male & III (78.7) & $59(78.6)$ & $52(78.8)$ & \\
\hline \multicolumn{5}{|l|}{ ECOG performance (N; \%) } \\
\hline 0 & $57(40.4)$ & $30(40.0)$ & $27(40.9)$ & 0.79 \\
\hline 1 & $84(59.6)$ & $45(60.0)$ & $39(59.1)$ & \\
\hline \multicolumn{5}{|l|}{ Tumor location (N; \%) } \\
\hline Head & II $5(81.6)$ & $61(81.3)$ & $54(81.8)$ & 0.87 \\
\hline Body/Tail & $26(18.4)$ & $14(18.7)$ & $12(18.2)$ & \\
\hline Median tumor size, $\mathrm{cm}$ (range) & $3.7(1.9-7.8)$ & $3.8(2.1-7.8)$ & $3.5(1.9-7.6)$ & 0.065 \\
\hline \multicolumn{5}{|l|}{$\mathrm{N}$-stage (N; \%) } \\
\hline 0 & $76(53.9)$ & $38(50.7)$ & $38(57.5)$ & 0.23 \\
\hline I & $65(46.1)$ & $37(49.3)$ & $28(42.5)$ & \\
\hline \multicolumn{5}{|l|}{ CA $19-9$ (N; \%) } \\
\hline$\leq 90 \mathrm{U} / \mathrm{mL}$ & $42(29.8)$ & $23(30.7)$ & $19(28.8)$ & 0.68 \\
\hline$>90 \mathrm{U} / \mathrm{mL}$ & $99(70.2)$ & $52(69.3)$ & 47 (7।.2) & \\
\hline Median BMI, kg/m² & 21.9 & 20.5 & 23.3 & 0.018 \\
\hline Median albumin, g/dL & 3.23 & 3.03 & 3.55 & 0.009 \\
\hline Median NLR & 2.76 & 3.18 & 2.28 & 0.003 \\
\hline
\end{tabular}

Abbreviations: ALI, Advanced lung cancer inflammation index; ECOG, Eastern Cooperative Oncology Group; N-stage, Nodal stage; CA 19-9, Cancer antigen 19-9; BMI, Body mass index; NLR, Neutrophil to lymphocyte ratio.

OS ( $\mathrm{P}<0.05$, for each factor) and PFS $(\mathrm{P}<0.05$, for each factor) results, respectively (Table 2).

\section{Discussion}

The results of current study clearly discovered the preCCRT ALI as a novel relevant prognosticator that assembled LAPC patients into two fundamentally distinct OS (25.8 versus 11.4 months; $\mathrm{P}<0.001)$ and PFS (15.9 versus 6.0 months; $\mathrm{P}<0.001)$ groups following radical CCRT, with results favoring ALI $>25.3$ over its $\leq 25.3$ counterpart.

In our present study, although the N-stage and CA 19-9 levels were also found to reliably predict clinical outcomes, yet the essential discovery of this first ALI investigation in LAPCs was the emergence of ALI $\geq 25.3$ as a novel and independent indicator of superior OS $(\mathrm{P}<0.001)$ and PFS $(\mathrm{P}<0.001)$ after radical CCRT., yet they Present results gave off an impression of being in great agreement with the results of previous ALI research in various tumor primaries (24-29), though it is quite difficult to achieve solid conclusions in absence of comparative LAPC studies. In the first of ever ALI study, Jafri et $\mathrm{al}^{24}$ reported that the median PFS (5.1 versus 2.4 months; $\mathrm{P}<0.001$ ) and OS (8.3 versus 3.4 months; $\mathrm{P}<0.001$ ) of 173 metastatic non-small-cell lung cancer patients who received palliative chemotherapy were essentially superior within the group with $\mathrm{ALI}>18$ as opposed to its $\mathrm{ALI} \leq 18$ partner. In a similar study, Feng et $\mathrm{al}^{25}$ utilized the same ALI cut-off for esophageal squamous cell carcinoma patients treated with surgery and found that the ALI $>18$ accomplices had significantly higher 5-year cancer-specific survival rate ( $43.4 \%$ versus $21.7 \%$; $\mathrm{P}<0.001$ ) than the $\mathrm{ALI} \leq 18$ companion. In a group of 365 small-cell lung cancer patients, He et $\mathrm{a}^{26}$ assigned the patients to one of ALI $\geq 19.5(\mathrm{~N}=305)$ or ALI $<19.5(\mathrm{~N}=60)$ groups and reported that the median OS was significantly longer in the ALI $\geq 19.5$ group (20.14 


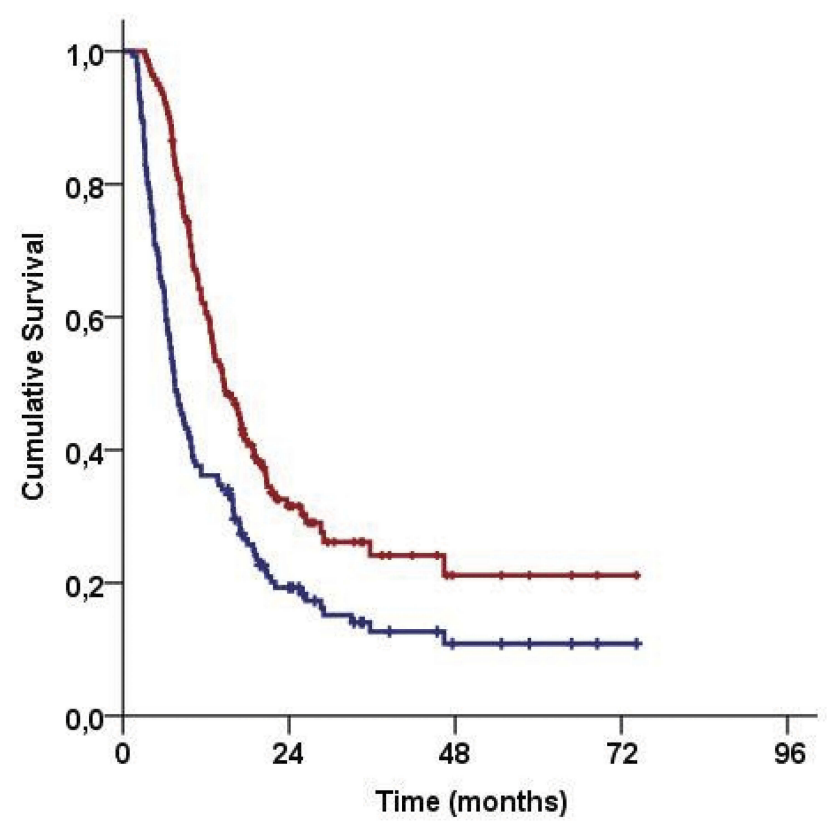

Figure I Survival outcomes for the entire study population (Red line: Overall survival; Blue line: Progression-free survival).

versus 10.97 months; $\mathrm{P}<0.001)$. Similarly, Jank et $\mathrm{al}^{27}$ reported that ALI $>37.6$ was significantly associated with superior 5-year disease-free survival (83.5\% versus 47.0; $\mathrm{P}<0.001)$ and $\mathrm{OS}(73.6 \%$ versus $44.4 ; \mathrm{P}=0.008)$ rates after postoperative radiotherapy in 93 head and neck squamous cell carcinomas. Shibutani et $\mathrm{al}^{28}$ reported significantly better OS rates for the group presenting with ALI $>28.9$ $(\mathrm{P}<0.0001)$ in 159 unresectable metastatic colorectal cancer patients who received combination chemotherapy. Finally, results of Park and colleagues ${ }^{29}$ study comprising 212 diffuse large B-cell lymphoma patients showed that ALI $>15.5$ was an independent predictor of longer PFS (77.3\% versus $58.1 \% ; \mathrm{P}=0.006)$ and $\mathrm{OS}(80.2 \%$ versus $64.2 \% ; \mathrm{P}=0.008)$. Taken together with these investigations, present results indicated the pre-CCRT ALI as a novel biomarker which can reliably predict PFS and OS of unresectable LAPC patients intended to receive radical CCRT, in like manner the other tumor primaries.

The BMI component of the ALI is unequivocally linked with cancer-related sarcopenia, and hence, cancerrelated cachexia syndrome which is an indicator of dreadful prognosis. But it might still be contended by some for its weakness for the exact impression of muscle versus fat composition. ${ }^{33,34}$ This contention is primarily based on the fact that some patients may have low muscle mass but paradoxically overall heavy body weight due to the highfat mass; a circumstance alluded to sarcopenic obesity. ${ }^{35,36}$
In any case, this issue was assessed by Shibutani et $\mathrm{al}^{28}$ and found that there was a significant correlation between the BMI and psoas muscle mass index, which is recognized as a more dependable objective measure of body muscle mass. ${ }^{37}$ Also, in a previous study Kim et $\mathrm{al}^{38}$ modified the ALI (mALI) by supplanting the BMI with CT-determined L3 muscle index (L3MI) to quantify the body mass more reliably in consecutively treated smallcell lung cancer patients. Nevertheless, the authors couldn't show any superiority of CT-determined L3MI based mALI over the original ALI and inferred that the original ALI was a simple but strong prognostic indicator of clinical outcomes. These particular findings both affirm and lend further support on the relevancy of our results displayed here, which proposed an excellent prognostic value for ALI in radically treated LAPC patients.

The precise mechanisms underlying the solid connection between the high ALI measures and significantly longer survival rates have not been clarified yet. Nevertheless, because the ALI incorporates BMI, albumin, and NLR, it is clear that ALI incorporates the factors playing pivotal roles in patients' nutritional, immune, and systemic inflammation status. Among these factors, both the low BMI and albumin measures furthermore mirror a pre-cachectic/ cachectic patient status that is firmly related with an overtly stimulated systemic inflammatory condition. ${ }^{39}$ Similarly, decreased levels of albumin and lymphocytes, and increased levels of neutrophils are altogether the systemic indicators of depressed host immunity with an accompanying overtly enhanced inflammatory condition. In this manner, low ALI levels robustly indicate a combination of poor nutritional and immune and exacerbated systemic inflammation status. In past examinations, every one of these three ominous conditions has been separately shown to be firmly connected with poorer clinical outcomes in many cancer types, including the LAPC. ${ }^{40,41}$ Among these indicators of the worse outcome, particularly the systemic inflammation, namely the seventh hallmark of cancer, is universally known to promote cellular proliferation, tumor growth, neo-angiogenesis, invasion, metastasis steps of carcinogenesis, and anti-apoptotic pathways. ${ }^{42,43}$ Furthermore, likely attributable to the overt activation of Kras, PC cells have higher basal levels of autophagy than the other cancer cells which promote tumor cell survival, growth, and invasiveness in stressful conditions such as chemotherapy/radiotherapy, nutrient deprivation, hypoxia, metabolic stress, and inflammation. ${ }^{4,45}$ In support, Yang et al showed that the $\mathrm{PC}$ was regressed with the inhibition of autophagy, which 

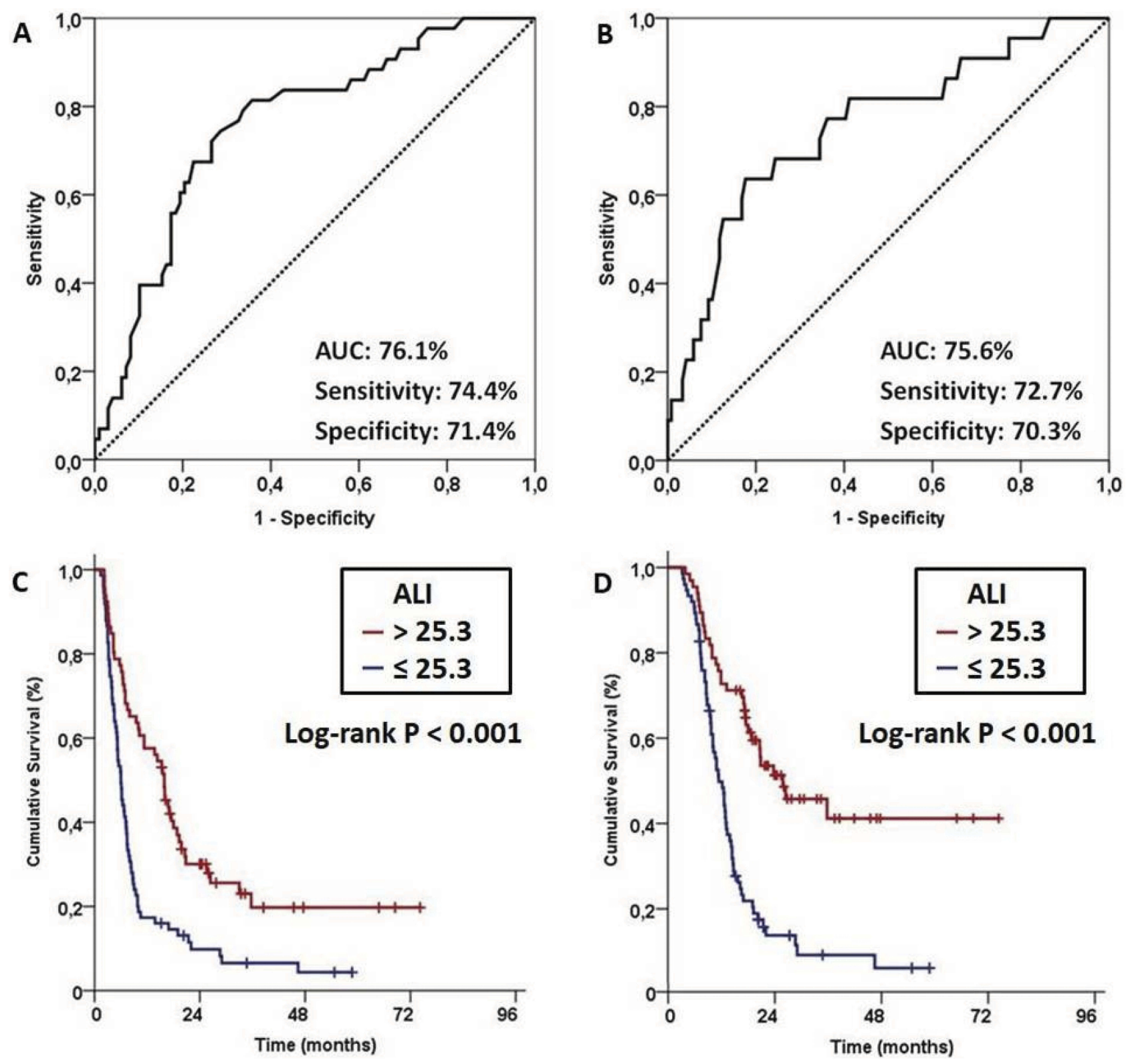

Figure 2 Outcomes of receiver operating characteristic (ROC) curve analyses and survival outcomes per advanced lung cancer inflammation index (ALI): (A) ROC curve analysis for progression- free survival, (B) ROC curve analysis for overall survival, (C) Progression-free survival, and (D) Overall survival.

was mediated by macrophage infiltration regulated by the cytokine secreting inflammation regulators. ${ }^{46}$ But, uninhibited autophagy was shown to conversely induce resistance to chemotherapy and radiotherapy. ${ }^{47,48}$ Consequently, in the light of accessible supporting literature, it is rational to anticipate that a low ALI predicts worse prognosis in radically treated LAPCs by reflecting altogether the hosts' poor nutritional and immune status, and unsuppressed systemic inflammation and autophagy in a highly inflammatory tumor microenvironment. However, despite the availability of rational basic knowledge, the definite connection between the ALI and autophagy in LAPC needs to be further studied before concluding more solidly on this particular issue.

The present study has at least two certain drawbacks. First, this is a single institutional retrospective cohort analysis in a relatively small study population; therefore, our results might be biased by various unpredictable tumor or patient-related factors. Accordingly, they must be valued as hypothetical and ought to be confirmed with future studies in order to remark more conclusively on the prognostic value of ALI in this patients group. And 
Table 2 Outcomes Of Uni- And Multivariate Analyses

\begin{tabular}{|c|c|c|c|c|c|c|}
\hline \multirow[t]{2}{*}{ Factor } & \multicolumn{3}{|l|}{ OS } & \multicolumn{3}{|l|}{ PFS } \\
\hline & Univariate P-Value & Multiivariate P-Value & HR & $\begin{array}{l}\text { Univariate } \\
\text { P-Value }\end{array}$ & $\begin{array}{l}\text { Multiivariate } \\
\text { P-Value }\end{array}$ & HR \\
\hline Age group (<70 vs $\geq 70 \mathrm{y}$ ) & 0.55 & - & - & 0.67 & - & - \\
\hline Gender (Female vs male) & 0.83 & - & - & 0.72 & - & - \\
\hline ECOG (0 vs I) & 0.74 & - & - & 0.63 & - & - \\
\hline Tumor location $(\mathrm{H}$ vs $B / T)$ & 0.87 & - & - & 0.79 & - & - \\
\hline Median tumor size $(<\mathrm{vs} \geq 3.7 \mathrm{~cm})$ & 0.41 & - & - & - & - & - \\
\hline $\mathrm{N}$-stage (0 vs I) & 0.002 & 0.007 & 1.89 & 0.008 & 0.014 & 1.67 \\
\hline CA $19-9$ (< vs $\geq 90 \mathrm{U} / \mathrm{m} / \mathrm{L})$ & 0.011 & 0.016 & 1.52 & 0.017 & 0.022 & 1.44 \\
\hline $\mathrm{ALI}(<\mathrm{vs} \geq 25.3)$ & $<0.001$ & $<0.001$ & 2.26 & $<0.001$ & $<0.001$ & 2.65 \\
\hline
\end{tabular}

Abbreviations: OS, Overall survival; PFS, Progression-free survival; HR, Hazard ratio; ECOG, Eastern Cooperative Oncology Group; H, Head; B/H, Body/tail; N-stage, Nodal stage; CA 19-9, Cancer antigen 19-9; ALI, Advanced lung cancer inflammation index.

Table 3 Survival Outcomes According To The Factors Exhibiting Independent Prognostic Value In Multivariate Analysis

\begin{tabular}{|c|c|c|c|c|c|c|c|c|c|}
\hline Survival & $\begin{array}{l}A L I<25.3 \\
(N=75)\end{array}$ & $\begin{array}{l}A L I \geq 25.3 \\
(N=66)\end{array}$ & P-Value & $\begin{array}{l}\text { No } \\
(\mathrm{N}=65)\end{array}$ & $\begin{array}{l}\mathrm{NI} \\
(\mathrm{N}=76)\end{array}$ & P-Value & $\begin{array}{l}\text { CA } 19-9 \leq 90 \mathrm{U} / \\
\mathrm{m} / \mathrm{L}(\mathrm{N}=48)\end{array}$ & $\begin{array}{l}\text { CA } 19-9>90 \mathrm{U} / \\
\mathrm{mL}(\mathrm{N}=93)\end{array}$ & P-Value \\
\hline OS & & & & & & & & & \multirow{4}{*}{0.016} \\
\hline Median, mo & 11.4 & 25.8 & $<0.001$ & 20.7 & 10.9 & 0.007 & 18.4 & 12.1 & \\
\hline 2-year (\%) & 13.8 & 51.3 & & 49.8 & II.I & & 43.8 & 26.7 & \\
\hline 4-year (\%) & 6.1 & 41.2 & & 32.6 & 8.8 & & 31.1 & 20.4 & \\
\hline \multicolumn{10}{|l|}{ PFS } \\
\hline Median, mo & 6.0 & 15.9 & $<0001$ & 10.0 & 6.0 & 0.014 & 9.2 & 6.4 & 0.022 \\
\hline 2-year (\%) & 9.8 & 30.1 & & 30.6 & 6.7 & & 28.6 & 15.2 & \\
\hline 4-year (\%) & 4.4 & 19.7 & & 16.7 & 5.0 & & 14.1 & 8.3 & \\
\hline
\end{tabular}

Abbreviations: ALI, Advanced lung cancer inflammation index; NO/I, Nodal stage 0/I; CA 19-9, Cancer antigen 19-9; OS, Overall survival; PFS, Progression-free survival.

second, although the ALI is a dynamic biological marker which may show remarkable variations during and postCCRT periods due to the changes in host immunity and systemic inflammation response status, and tumor load, yet our research was limited to the pre-CCRT ALI calculations. Since the dynamic ALI fluctuations at any time point during or after the CCRT may reflect either the tumor response or progression much earlier than the emergence of unequivocal radiographic changes; the subsequent studies should particularly concentrate on the ALI dynamics in order to define more relevant cutoff(s) which might serve further useful in prognostic stratification of LAPC patients after CCRT.

\section{Conclusion}

The results of this hypothesis-generating retrospective investigation proposed that the pre-CCRT ALI was robustly associated with OS and PFS outcomes in LAPC patients treated with radical CCRT. Hence, if confirmed with further large scale studies, ALI may conceivably be utilized together with the TNM staging system to enhance the prognostic strength of this universally appreciated framework.

\section{Data Sharing Statement}

Data cannot be shared publicly because the data is owned and saved by Baskent University Medical Faculty. Data are available from the Baskent University Medical Faculty Institutional Data Access/Ethics Committee (contact via Baskent University Ethics Committee) for researchers who meet the criteria for access to confidential data: contact address, adanabaskent@baskent.edu.tr.

\section{Author Contributions}

All authors contributed to data analysis, drafting or revising the article, gave final approval of the version to be published, and agree to be accountable for all aspects of the work. 


\section{Disclosure}

The authors report no conflicts of interest in this work.

\section{References}

1. Klaassen DJ, MacIntyre JM, Catton GE, Engstrom PF, Moertel CG. Treatment of locally unresectable cancer of the stomach and pancreas: a randomized comparison of 5-fluorouracil alone with radiation plus concurrent and maintenance 5-fluorouracil-an Eastern Cooperative Oncology Group study. J Clin Oncol. 1985;3:373-378. doi:10.1200/ JCO.1985.3.3.373

2. Gastrointestinal Tumor Study Group. Radiation therapy combined with adriamycin or 5-fluorouracil for the treatment of locally unresectable pancreatic carcinoma. Cancer. 1985;56:2563-2568. doi:10.1002/10970142(19851201)56:11<2563::aid-cncr2820561104>3.0.co;2-0

3. Gudjonsson B. Cancer of the pancreas. 50 years of surgery. Cancer. 1987;60(9):2284-2303. doi:10.1002/1097-0142(19871101)60:9<2284:: aid-cncr2820600930>3.0.co;2-v

4. Russo S, Butler J, Ove R, Blackstock AW. Locally advanced pancreatic cancer: a review. Semin Oncol. 2007;34:327-334. doi:10.1053/j. seminoncol.2007.05.007

5. Huguet F, Girard N, Guerche CS, Hennequin C, Mornex F, Azria D. Chemoradiotherapy in the management of locally advanced pancreatic carcinoma: a qualitative systematic review. J Clin Oncol. 2009;27:2269-2277. doi:10.1200/JCO.2008.19.7921

6. Parsons CM, Sutcliffe JL, Bold RJ. Preoperative evaluation of pancreatic adenocarcinoma. $J$ Hepatobiliary Pancreat Surg. 2008;15:429-435. doi:10.1007/s00534-007-1240-7

7. Hanahan D, Weinberg RA. Hallmarks of cancer: the next generation. Cell. 2011;144:646-674. doi:10.1016/j.cell.2011.02.013

8. Liu Z, Jin K, Guo M, et al. Prognostic value of the CRP/Alb ratio, a novel inflammation-based score in pancreatic cancer. Ann Surg Oncol. 2017;24(2):561-568. doi:10.1245/s10434-016-5579-3

9. Yadav D, Lowenfels AB. The epidemiology of pancreatitis and pancreatic cancer. Gastroenterology. 2013;144:1252-1261. doi:10.1053/j. gastro.2013.01.068

10. Birtolo C, Go VL, Ptasznik A, et al. Phosphatidylinositol 3-Kinase: a link betweeninflammation and pancreatic cancer. Pancreas. 2016;45 (1):21-31. doi:10.1097/MPA.0000000000000531

11. Martin HL, Ohara K, Kiberu A, et al. Prognostic value of systemic inflammation-based markers in advanced pancreatic cancer. Intern Med J. 2014;44(7):676-682. doi:10.1111/imj.12453

12. Steele CW, Jamieson NB, Evans TR, et al. Exploiting inflammation for therapeutic gain in pancreatic cancer. Br J Cancer. 2013;108 (5):997-1003. doi:10.1038/bjc.2013.24

13. McMillan DC. The systemic inflammation-based Glasgow Prognostic Score: a decade of experience in patients with cancer. Cancer Treat Rev. 2013;39(5):534-540. doi:10.1016/j.ctrv.2012.08.003

14. Zambirinis CP, Pushalkar S, Saxena D, Miller G. Pancreatic cancer, inflammation, and microbiome. Cancer J. 2014;20(3):195-202. doi:10.1097/PPO.0000000000000045

15. Garcea G, Ladwa N, Neal CP, et al. Preoperative neutrophil to lymphocyte ratio (NLR) is associated with reduced disease-free survival following curative resection of pancreatic adenocarcinoma. World J Surg. 2011;35:868-872. doi:10.1007/s00268-011-0984-z

16. Wang DS, Luo HY, Qiu MZ, et al. Comparison of the prognostic values of various inflammation based factors in patients with pancreatic cancer. Med Oncol. 2012;29:3092-3100. doi:10.1007/s12032-012-0226-8

17. Smith RA, Bosonnet L, Raraty M, et al. Preoperative platelet-lymphocyte ratio is an independent significant prognostic marker in resected pancreatic ductal adenocarcinoma. Am J Surg. 2009;197:466-472. doi:10.1016/j.amjsurg.2007.12.057
18. Bhatti I, Peacock O, Lloyd G, et al. Preoperative hematologic markers as independent predictors of prognosis in resected pancreatic ductal adenocarcinoma: neutrophil-lymphocyte versus platelet-lymphocyte ratio. Am J Surg. 2010;200:197-203. doi:10.1016/j.amjsurg.2009.08.041

19. Stotz M, Gerger A, Eisner F, et al. Increased neutrophil-lymphocyte ratio is a poor prognostic factor in patients with primary operable and inoperable pancreatic cancer. Br J Cancer. 2013;109:416-421. doi:10.1038/bjc.2013.332

20. Shimizu T, Taniguchi K, Asakuma M, et al. Lymphocyte-tomonocyte ratio and prognostic nutritional index predict poor prognosis in patients on chemotherapy for unresectable pancreatic cancer. Anticancer Res. 2019;39(4):2169-2176. doi:10.21873/ anticanres. 13331

21. Yamada S, Fujii T, Yabusaki N, et al. Clinical implication of inflammation-based prognostic score in pancreatic cancer: glasgow prognostic score is the most reliable parameter. Medicine (Baltimore). 2016;95(18):e3582. doi:10.1097/MD.0000000000004864

22. Geng Y, Qi Q, Sun M, et al. Prognostic nutritional index predicts survival and correlates with systemic inflammatory response in advanced pancreatic cancer. Eur J Surg Oncol. 2015;41(11):15081514. doi:10.1016/j.ejso.2015.07.022

23. Qi Q, Zhuang L, Shen Y, et al. A novel systemic inflammation response index (SIRI) for predicting the survival of patients with pancreatic cancer after chemotherapy. Cancer. 2016;122(14):21582167. doi:10.1002/cncr.30057

24. Jafri SH, Shi R, Mills G. Advance lung cancer inflammation index (ALI) at diagnosis is a prognostic marker in patients with metastatic non-small cell lung cancer (NSCLC): a retrospective review. $B M C$ Cancer. 2013;13:158. doi:10.1186/1471-2407-13-158

25. Feng JF, Huang Y, Chen QX. A new inflammation index is useful for patients with esophageal squamous-cell carcinoma. Onco Targets Ther. 2014;7:1811-1815. doi:10.2147/OTT.S68084

26. He X, Zhou T, Yang Y, et al. Advanced lung cancer inflammation index, a new prognostic score, predicts outcome in patients with small-cell lung cancer. Clin Lung Cancer. 2015;16:e165-e171. doi:10.1016/j.cllc.2015.03.005

27. Jank BJ, Kadletz L, Schnöll J, et al. Prognostic value of advanced lung cancer inflammation index in head and neck squamous-cell carcinoma. Eur Arch Otorhinolaryngol. 2019;276(5):1487-1492. doi:10.1007/s00405-019-05381-0

28. Shibutani M, Maeda K, Nagahara H, et al. The prognostic significance of the advanced lung cancer inflammation index in patients with unresectable metastatic colorectal cancer: a retrospective study. BMC Cancer. 2019;19(1):241. doi:10.1186/s12885-019-5468-9

29. Park YH, Yi HG, Lee MH, Kim CS, Lim JH. Prognostic value of the pretreatment advanced lung cancer inflammation index (ALI) in diffuse large B-cell lymphoma patients treated with R-CHOP chemotherapy. Acta Haematol. 2017;137:76-85. doi:10.1159/000452991

30. Topkan E, Yavuz AA, Aydin M, et al. Comparison of CT and PET-CT based planning of radiation therapy in locally advanced pancreatic carcinoma. J Exp Clin Cancer Res. 2008;27:41. doi:10.1186/17569966-27-41

31. Yildirim BA, Özdemir Y, Colakoglu T, Topkan E. Impact of presence and degree of pretreatment weight loss in locally-advanced pancreatic cancer patients treated with definitive concurrent chemoradiotherapy. Pancreatology. 2016;16(4):599-604. doi:10.1016/j.pan.2016.03.006

32. Oettle H, Post S, Neuhaus P, et al. Adjuvant chemotherapy with gemcitabine vsobservation in patients undergoing curative-intent resection of pancreatic cancer: a randomized controlled trial. JAMA. 2007;297(3):267-277. doi:10.1001/jama.297.3.267

33. Levolger S, van Vugt JL, de Bruin RW, IJzermans JN. Systematic review of sarcopenia in patients operated on for gastrointestinal and hepatopancreatobiliary malignancies. Br J Surg. 2015;102:14481458. doi:10.1002/bjs. 9893 
34. Kim EY, Kim YS, Seo JY, et al. The relationship between sarcopenia and systemic inflammatory response for cancer cachexia in small cell lung cancer. PLoS One. 2016;11:e0161125. doi:10.1371/journal.pone.0161125

35. Hilmi M, Jouinot A, Burns R, et al. Body composition and sarcopenia: the nextgeneration of personalized oncology and pharmacology? Pharmacol Ther. 2019;196:135-159. doi:10.1016/j.pharmthera.2018.12.003

36. Baracos VE, Arribas L. Sarcopenicobesity: hidden muscle wasting and its impact for survival and complications of cancer therapy. Ann Oncol. 2018;29(suppl-2):ii1-ii9. doi:10.1093/annonc/mdx810

37. Hamaguchi Y, Kaido T, Okumura S, et al. Proposal for new diagnostic criteria for low skeletal muscle mass based on computed tomography imaging in Asian adults. Nutrition. 2016;23:1200 1205. doi:10.1016/j.nut.2016.04.003

38. Kim EY, Kim N, Kim YS, et al. Prognostic significance of modified advanced lung cancer inflammation index (ALI) in patients with small cell lung cancer- Comparison with original ALI. PLoS One. 2016;11(10):e0164056. doi:10.1371/journal.pone.0164056

39. Evans WJ, Morley JE, Argil'es J, et al. Cachexia: a new definition. Clin Nutr. 2008;27(6):793-799. doi:10.1016/j.clnu.2008.06.013

40. Cole CL, Kleckner IR, Jatoi A, Schwarz EM, Dunne RF. The role of systemic inflammation in cancer-associated muscle wasting and rationale for exercise as a therapeutic intervention. JCSM Clin Rep. 2018;3(2):pii: e00065.

41. Bałan BJ, Zygmanowska E, Radomska-Leśniewska DM. Disorders noticed during development of pancreatic cancer: potential opportunities for early and effective diagnostics and therapy. Cent Eur J Immunol. 2017;42(4):377-382. doi:10.5114/ceji.2017.68698
42. Tenesa A, Theodoratou E, Din FV, et al. Ten common genetic variants associated with colorectal cancer risk are not associated with survival after diagnosis. Clin Cancer Res. 2010;16(14):37543759. doi:10.1158/1078-0432.CCR-10-0439

43. Colotta F, Allavena P, Sica A, et al. Cancer related inflammation, the seventh hallmark of cancer: links to genetic instability. Carcinogenesis. 2009;30(7):1073-1081. doi:10.1093/carcin/bgp127

44. Yang S, Wang X, Contino G, et al. Pancreatic cancers require autophagy for tumor growth. Genes Dev. 2011;25(7):717-729. doi:10.1101/gad.2016111

45. Aghajan M, Li N, Karin M. Obesity, autophagy and the pathogenesis of liver and pancreatic cancers. $J$ Gastroenterol Hepatol. 2012;27Suppl 2:10-14. doi:10.1111/j.1440-1746.2011.07008.x

46. Yang A, Herter-Sprie G, Zhang H, et al. Autophagy sustains pancreatic cancer growth through both cell autonomous and non-autonomous mechanisms. Cancer Discov. 2018;8:276-287. doi:10.1158/ 2159-8290.CD-17-0952

47. Saglar E, Unlu S, Babalioglu I, Gokce SC, Mergen H. Assessment of ER Stress and autophagy induced by ionizing radiation in both radiotherapy patients and ex vivo irradiated samples. $J$ Biochem $\mathrm{Mol}$ Toxicol. 2014;28(9):413-417.

48. Mukubou H, Tsujimura T, Sasaki R, Ku Y. The role of autophagy in the treatment of pancreatic cancer with gemcitabine and ionizing radiation. Int $J$ Oncol. 2010;37(4):821-828. doi:10.3892/ ijo_00000732

\section{Publish your work in this journal}

Cancer Management and Research is an international, peer-reviewed open access journal focusing on cancer research and the optimal use of preventative and integrated treatment interventions to achieve improved outcomes, enhanced survival and quality of life for the cancer patient.
The manuscript management system is completely online and includes a very quick and fair peer-review system, which is all easy to use. Visit http://www.dovepress.com/testimonials.php to read real quotes from published authors. 